
\title{
Spontan Hemotoraks
}

\author{
Spontaneous Hemothorax due to Oral Anticoagulant Therapy
}

Hasan Kahraman, ${ }^{1}$ Nurhan Atilla, ${ }^{2}$ Selim Bozkurt, ${ }^{3}$ Burcu Yormaz, ${ }^{1}$ Mustafa Haki Sucaklı, ${ }^{4}$ Hatice Şahin, Mahmut Tokur 5

\section{Özet}

Oral antikoagülan tedavisi yaygın bir şekilde birçok hastalık durumunda kullanılmaktadır ve en sık kullanılan etken madde ise varfarin'dir. Varfarin kullanımının en önemli komplikasyonu kanamadır ve bu komplikasyonun nadir bir formu ise spontan hemotoraks'dır. Olgumuz 53 yaşında bayan hasta, derin ven trombozu ve pulmoner emboli tanıları ile varfarin tedavisi almakta idi. International Normalized Ratio (INR) değeri 2,84 ve beklenen aralıkta (2-3) idi. Tedavinin üçüncü ayında hastamızda nadir komplikasyon olan spontan hemotoraks gelişti. Antikoagülan kullanılmasından dolayı hastamıza göğ̈̈s tüpü takılmadı ve tekrarlanan teropötik torasentezler ile hemotoraks tedavi edildi. Bu olguda da görüldüğü gibi oral antikoagülan kullanan hastalarda INR değeri normal olsa bile kanamanın gelişebileceğini ve hemotoraksın tedavi seçenekleri arasında terapötik torasentezin de olabileceğini vurgulamak istedik.

Anahtar Sözcükler: Varfarin, hemotoraks, terapötik torasentez.

\begin{abstract}
Oral anticoagulant treatment is widely used in many diseases, with warfarin being the most commonly used active ingredient. The most important complication of warfarin use is bleeding and a rare form of this complication is spontaneous hemothorax. The current case was a 53-year-old female patient receiving warfarin therapy with the diagnosis of deep vein thrombosis and pulmonary embolism. The value of her International Normalized Ratio (INR) was 2.84, and within the expected range (2-3). At the third month of the treatment, the patient developed a rare complication of spontaneous hemothorax. Due to the use of an oral anticoagulant, a chest tube was not inserted in the patient and hemothorax was treated with repeat therapeutic thoracentesis. In this case, the researchers wanted to emphasize that in patients treated with oral anticoagulants, INR, even if normal, bleeding may develop and therapeutic thoracentesis is the one of the treatment options for hemothorax.
\end{abstract}

Key words: Warfarin, hemothorax, therapeutic thoracentesis.

'Department of Chest Disease, Kahramanmaraş Sütçü İmam University Faculty of Medicine, Kahramanmaraş, Turkey

2Department of Chest Disease, Kahramanmaraş State Hospital, Kahramanmaraş, Turkey

${ }^{3}$ Department of Emergency Medicine, Kahramanmaraş Sütçü İmam University Faculty of Medicine, Kahramanmaraş, Turkey

${ }^{4}$ Department of Family Medicine, Kahramanmaraş Sütçü İmam University, Faculty of Medicine, Kahramanmaraş, Turkey

${ }^{5}$ Department of Chest Surgery, Kahramanmaraş Sütçü İmam University Faculty of Medicine, Kahramanmaraş, Turkey

Submitted (Başvuru tarihi): 16.05.2013 Accepted (Kabul tarihi): 20.06.2013

Correspondence (iletişim): Hasan Kahraman, Kahramanmaraş Sütçü İmam Üniversitesi, Tıp Fakültesi, Göğüs

Hastalıkları Anabilim Dalı, Kahramanmaraş

e-mail: drhasankahraman@hotmail.com 
Vitamin $\mathrm{K}$ antagonistleri, 60 yılı aşkın süredir oral antikoagülan tedavi olarak kullanılmaktadır. En sık kullanılan etken madde ise varfarin'dir. Varfarin'in, primer ve sekonder venöz tromboemboli profilaksisinde, prostetik kalp kapağı veya atriyal fibrilasyon durumunda sistemik embolinin önlenmesinde, miyokard infarktüsü sonrası sistemik embolinin önlenmesinde ve rekürren miyokard infarktüsü riskini azaltmada etkili olduğu gösterilmiştir. Dar terapötik penceresi olması, genetik ve diğer faktörler nedeniyle hastalar arasında doz-yanıt arasında önemli değişkenlik göstermesi, ilaçlar ve diyet ile etkileşime girmesi gibi nedenlerle klinik pratikte kullanımı zor bir ilaçır (1). Kanama en önemli komplikasyonu olmasına rağmen hemotoraks gelişimi oldukça nadirdir. Olgumuzu, varfarin tedavisi alırken, International Normalized Ratio (INR) değeri normal olmasına rağmen hemotoraks komplikasyonu gelişmesi, hemotoraks tedavisi için ise terapötik torasentez uygulanması ve bu durumun nadir görülmesi sebebiyle sunuyoruz.

\section{OLGU}

Elli üç yaşında bayan hasta bir ay önce başlayan nefes darlığı, öksürük, sağ yan ağrısı, ateş yakınmaları ile bir merkezde pnömoni tanısı almış ve yatarak tedavi görmüş, 15 gün sonra sol bacakta ağrı ve şişlik olunca Hastanemiz Kalp Damar Cerrahi Polikliniğine başvurmuş ve yapılan bilateral alt ekstremite venöz dopler tetkiki sonucunda sol yüzeyel femoral ven orta kesiminden itibaren sol popliteal ven ve dallarında akut derin ven trombozu saptanmış ve solunum yolu ile ilgili şikâyetleri olması üzerine polikliniğimize konsülte edilmiştir. Hastanın öksürük, sağ yan ağrısı ve nefes darlığı şikâyetleri devam etmekte idi. Özgeçmişinde, miyom, bel ve boyun fitı̆ı̆ dışında ek bir hastalığı yoktu. Sigara ve alkol alışkanlığı bulunmamaktaydı. Fizik muayenesinde; arteryel kan basıncı 90/60 $\mathrm{mmHg}$, nabız 145 /dakika-ritmik ve solunum seslerinde yer yer kabalaşma mevcuttu. PA akciğer grafisinde sağ sinüs kapalı olup minimal plevral efüzyon izlendi (Şekil 1a). Pulmoner BT anjiyoda sağ akciğer alt loba giden segmenter dal total tromboze olup subsegmenter dallarda akım izlenmedi; sol akciğer üst lob anteriora giden subsegmenter dal parsiyel alt loba giden pulmoner arter dalı subtotal tromboze halde izlendi. Sağ hemitoraksta en derin yerinde $34 \mathrm{~mm}$ ölçülen plevral efüzyon ve aynı taraf alt lob mediobazal ve laterobazal segmentlerde lineer atelektazik alanlar izlendi (Şekil 1b). Hastanın ekokardiyografisinde $\mathrm{EF}: \% 60$, pulmoner arteryel basınç 60 $\mathrm{mmHg}$ idi. Arteryel kan analizinde $\mathrm{pH}: 7,48, \mathrm{PaO}_{2}: 63$ $\mathrm{mmHg}, \mathrm{PaCO}_{2}: 38,6 \mathrm{mmHg}$ ve $\mathrm{SaO}_{2}$ : \%93 idi. Labora- tuvar incelemesinde $\mathrm{Hb}: 11,8 \mathrm{~g} / \mathrm{dL}$, Hct: \%34,2, trombosit: $212.000 / \mathrm{dL}$, lökosit: $7.000 / \mathrm{dL}$ idi. Kan biyokimya tahlilleri normaldi. PT: 13,1 saniye ( $\mathrm{N}: 11-16$ saniye) ve INR değeri: 1,18 (N:0.8-1.2) idi. Hasta pulmoner emboli tanısıyla kliniğimize yatıııldı ve enoksaparin sodyum ile antikoagulan tedavisine başlandı. Hastaya varfarin ilave edilip INR değeri 2-3 arasında olduktan sonra taburcu edildi. Takipleri sırasında varfarin tedavisinin üçüncü ayında hastada sağ göğüs ağrısı ve nefes darlığı tekrar başlamış. Yedi gün sonra acile geldiğinde, fizik muayenesinde sağ hemitoraksta skapula altında solunum sesleri ve vibrasyon torasikte azalma, bunula birlikte perküzyonda matite saptandı. Arteryel kan basıncı 110/70 mmHg ve nabız 112 /dakika ve ritmikti. Laboratuvar tahlillerinde; $\mathrm{Hb}: 11,5 \mathrm{~g} / \mathrm{dL}$; Hct: \%34,9; trombosit: $413.000 / \mathrm{dL}$; lökosit: $8.000 / \mathrm{dL}$ idi. Kan biyokimyası ve idrar analizi normaldi. Bakılan INR değeri 2,84 olarak saptandı. PA akciğer grafisinde sağda plevral efüzyonun belirgin artması üzerine hasta servise tekrar yatııılı (Şekil 2a). Çekilen toraks BT de sağ hemitoraksta orta zon anterior posteriordan başlayıp bazale dek uzanan en geniş yerinde 8 $\mathrm{mm}$ çapa ulaşan plevral efüzyon izlendi (Şekil 2b). Varfarin kesildi ve enoksaparin sodyum başlandı. INR seviyesi normale gelmesi ile torasentez yapıldı ve sıvı hemorajik olarak saptandı. Plevral sıvı incelenmesinde; lökosit: $1.570 / \mathrm{dL} ; \mathrm{Hb}: 12,4 \mathrm{~g} / \mathrm{dL}$; Hct: \%41,7; trombosit: $31.000 / \mathrm{dL}$ idi. Hastaya antikoagulan tedavi alması sebebi ile göğüs drenaj tüpü takılmadı. Aralıklı plevral drenaj ile üç defada toplam $700 \mathrm{cc}$ hemorajik mayii boşaltıldı. Plevral sıvı sitolojisinde yoğun kan elemanları ile birlikte arada az sayıda lenfosit ve mezotel hücreleri izlendi. Hastada hemotoraks gelişmesinden iki hafta önce kontrole geldiğindeki tahlillerde; $\mathrm{Hb} 13,1, \mathrm{Hct}$ : \%39,4 ve INR değeri ise 3,01 idi ve diğer tahliller normaldi. Hemotoraks gelişmesini etkileyebilecek herhangi bir ilaç kullanımı veya travma öyküsü olup olmadığı araşsıııldı, ama saptanmadı. Radyolojik düzelme izlenen hastamı, hemotoraks boşaltıldıktan beş gün sonra enoksaparin sodyum tedavisi ile taburcu edildi (Şekil 3). Hastanın takiplerinde iki ay sonraki filminde regresyonun devam ettiği ve sağ akciğerde volüm kaybının başladığı saptandı (Şekil 4).

\section{TARTIŞMA}

Varfarin oral antikoagülanlardan biridir ve $\mathrm{K}$ vitamininin etkilerini antagonize ederek etkisini göstermektedir. Etkisinin tam olarak ortaya çıkması için en az 48-72 saat gereklidir (2). Biyoyararlanımı \%100'e yakındır ve gastrointestinal sistemden emilimi için safraya ihtiyaç vardır. Plazmada \%99 oranında albümine bağlıdır ve serbest 
olan kısım aktiftir, renal eliminasyonu yavaşıı. Plazma yarılanma süresi 36 saattir ve klinik takibinde, INR değeri kullanılmaktadır (2).
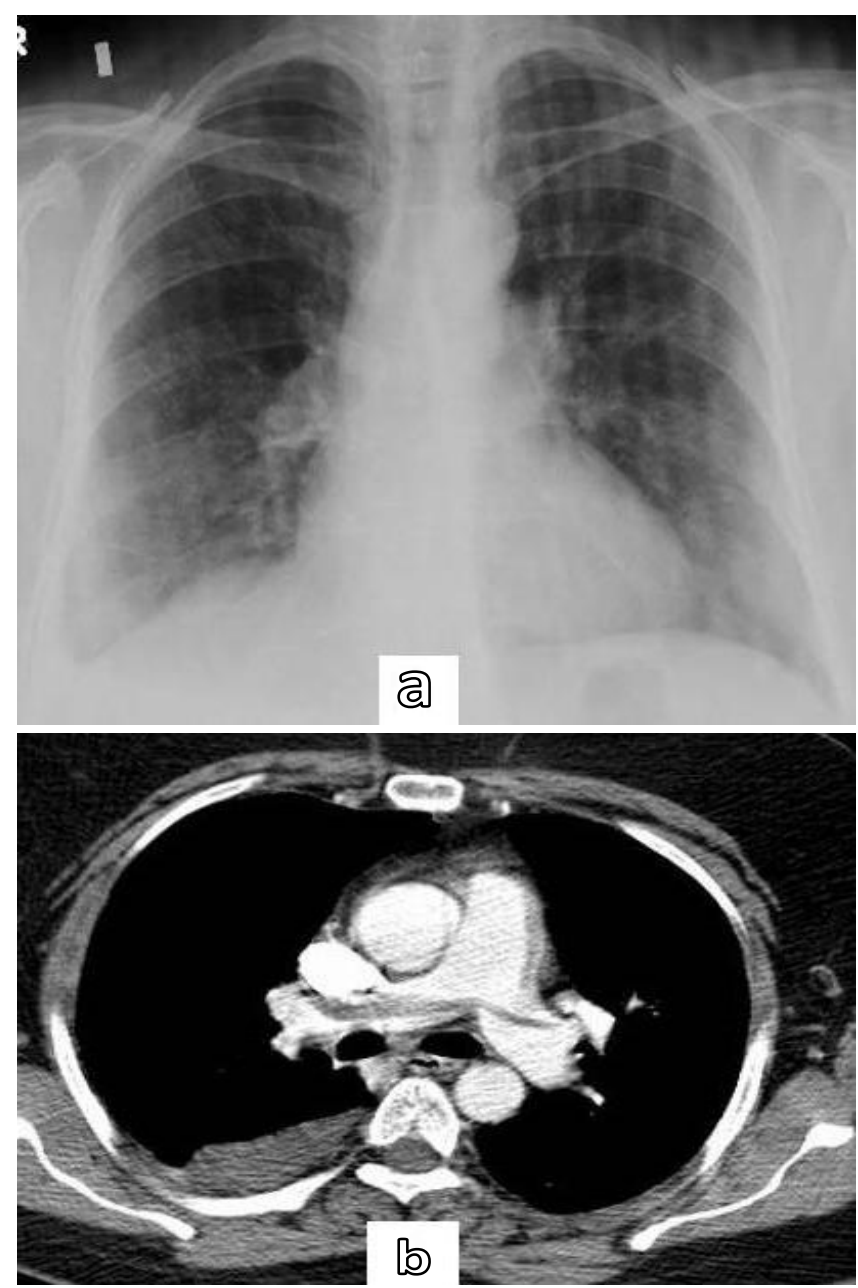

Şekil 1a, b: Emboli saptanan hastanın a) PA akciğer grafisinde sağ sinüs kapalı olup minimal plevral efüzyon, b) BT anjiyografide sağ akciğere giden pulmoner arterde emboli ve aynı tarafta plevral efüzyon.

Varfarin; venöz tromboz, pulmoner emboli, atriyal fibrilasyon ve/veya kalp kapak replasmanı ile ilişkili tromboembolik komplikasyonların önlenmesinde ve tedavisinde dünya genelinde sık kullanılan bir ilaçtır. Kanama varfarin tedavisinin yaygın ve en ciddi komplikasyonudur ve majör ve minör kanama olarak sıniflandırılır (3). Intrakraniyal, ölüm veya hospitalizasyon gerektiren kanama majör kanama olarak tanımlanır. Kanama riskini etkileyen en önemli faktör antikoagülan tedavi yoğunluğu olup, INR düzeyi majör belirleyicidir (4). Veeger ve ark. (5) bir çalışmada varfarin kullanan toplam 2304 hastanın 40'ında $(\% 1,7)$ majör kanama komplikasyonu rastlamış ve cinsiyete baktıklarında \%88'inin kadın olduğunu, INR düzeyi 1-2 arasında olanlarda yıllık kanama insidansı \%0,4, 2-3 olanlarda \%1,0, 3-4 olanlarda \%1,2, 4-5 olanlarda \% $1,3,>5$ olanlarda $\% 6,4$ olarak saptamışlardır. Palareti ve ark'nın (6) yaptıkları başka bir çalışmada, INR düzeyi 2-2,9'dan 3,0-4,4'e çıkłığında kanama komplikasyonunun iki kat, 4,5-6,0'na çıkıı̆ında ise dört kat arttığını saptamıştır. Varfarin için ideal INR değerinin 2-3 arası olması gerektiği birçok çalışmada bildirilmiştir $(1,7)$. Bununla birlikte Hollanda antikoagülan klinikleri ise INR değerini 2-3,5 arasında tutmanın uygun olacağını belirtmektedirler (8). Ülkemizde yapılan varfarin kullanma sırasında kanama saptanan 105 olgunun incelemesinde \%21,9'unda INR düzeyi 3,5 ve altında idi (2). Olgumuzda tedavi boyunca INR değerleri genelde 2-3 arasında idi. Hastamı hemotoraks belirtileri ile geldiğinde INR değeri 2,84 hemoglobin değeri 11,5 idi; 2 hafta önce kontrole geldiğindeki INR değeri, 3,01 ve hemoglobin değeri 13,1 idi. Olgumuzda da görüldüğü gibi INR değeri normal sınırlarda olsa bile hastada kanama komplikasyonu gelişebileceği unutulmamalıdır. Belirgin bulgu vermeyen okült kanamaların varlığında, kanamanın tespiti için hemoglobin takibinin rutin yapılmasının uygun olacağını kanaatindeyiz.
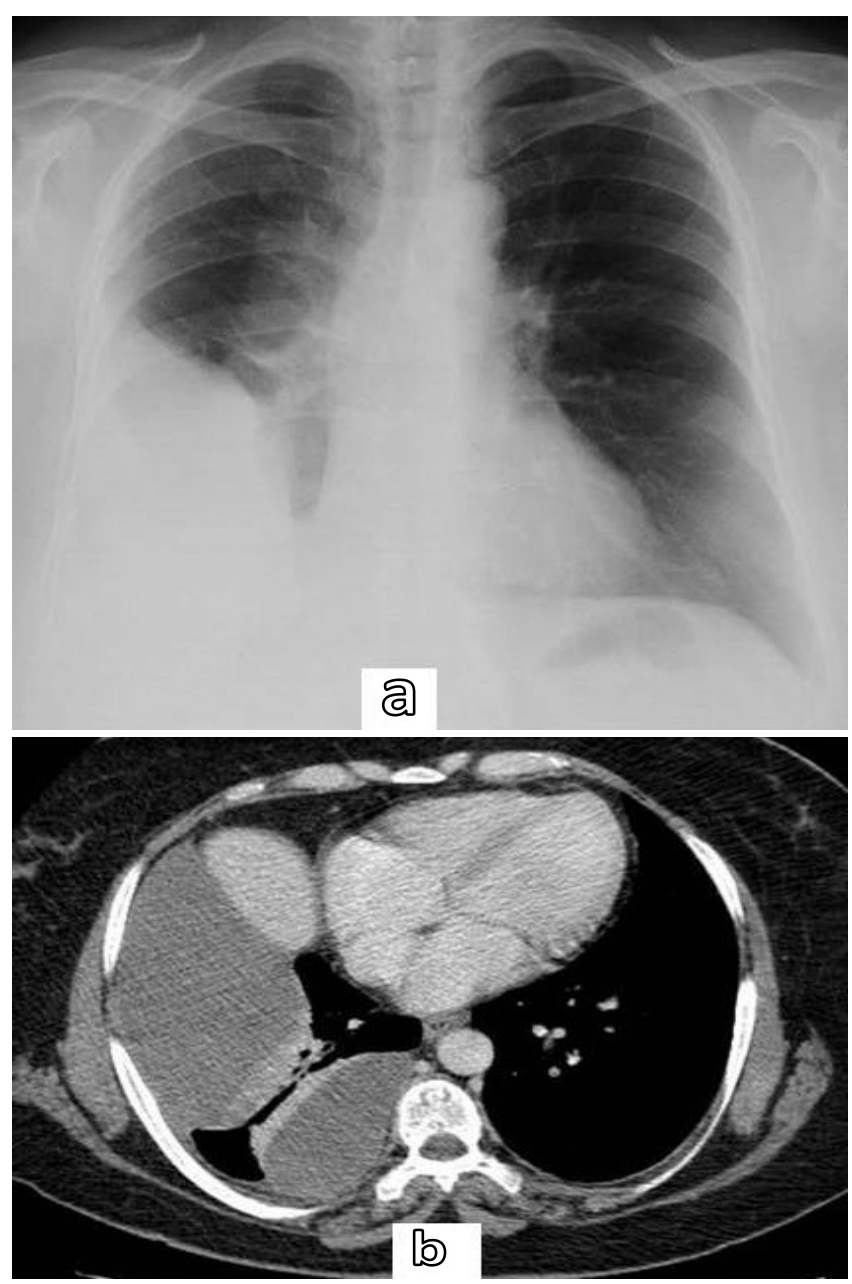

Şekil 2a, b: Hemotoraks saptanan hastanın a) PA akciğer grafisinde sağda plevral efüzyonda belirgin artış, b) toraks BT de sağ hemitoraksta orta zondan başlayıp bazale dek uzanan en geniş yerinde $8 \mathrm{~mm}$ çapa ulaşan loküle plevral efüzyon odakları. 
Yapılan bir çalışmada, heparin tedavisi sırasında ölümcül, majör, majör ve minör kanama ortalama yıllık frekansları sırasıyla $\% 0,05, \% 0,8$ ve $\% 2,0$ olduğunu ve varfarin tedavisi sırasında ise bu oranların sırasıyla \%0,6, \%3,0 ve $\% 9,6$ olduğunu belirtmektedir (7). Antikoagülan ile ilgili kanama riski en yüksek tedavinin erken dönemlerinde gözükmektedir. Warfarin tedavisi sırasında majör kanama, tedavinin ilk ayında gelişme riski tedavinin ilk yılından sonraki sürede gelişmesinden yaklaşık 10 katı olduğu saptanmıştır. Yine aynı çalışmada, hastaya ait faktörlere bakıldığında majör kanama, en çok ulaşılan INR düzeyi ve özellikle serebrovasküler, böbrek, kalp ve karaciğer hastalığı gibi eşlik eden ciddi hastalıkların varlığı, ileri yaş ve eşzamanlı ilaç kullanımları olarak belirtilmektedir (7). Bizim hastamızda herhangi bir kronik hastalık öyküsü yoktu ve yaşlıda değildi. Hemotoraks gelişmesinden önce herhangi bir ilaç kullanımı da saptanmamıştı.

Pulmoner tromboembolizmin (PTE) her yıl 100.000 kişiden en az 250'sinde görüldüğü tahmin edilmektedir. PTE hastaların \%30 ile \%50'sinde plevral efüzyon gözükmektedir ve plevral efüzyonun ayırıcı tanısında pek düşünülmeyen bir durumdur. PTE'de plevral efüzyon genelde tek taraflı ve az miktarda olması beklenmektedir. Loküle plevral efüzyon özellikle inflamasyonun fazla olduğu komplike parapnömonik plevral efüzyon, malign plevral efüzyon ve daha nadir olarak da hemotoraks gibi durumlarda gözlenmektedir $(9,10)$. Olgumuzda geliş filminde belirgin olmayan plevral efüzyon saptandı ve PTE durumuna bağlı olduğu düşünüldü. Takiplerinde aniden efüzyon seviyesinde artış olması ve $B T^{\prime}$ de loküle şekilde gözükmesi sebebi ile ponksiyon yapıldı ve hemotoraks saptandı.

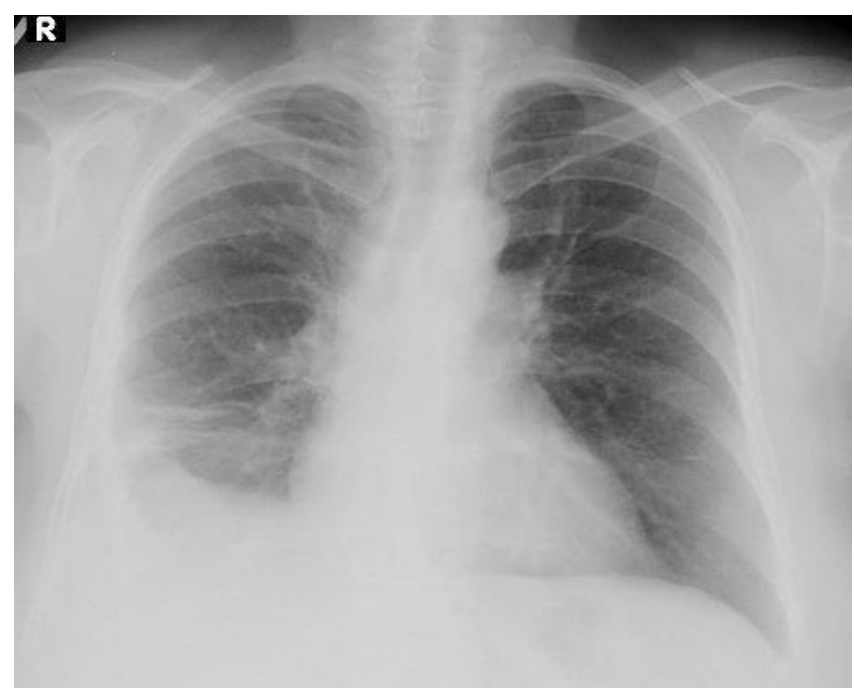

Şekil 3: PA akciğer gafisinde hemotoraks miktarında belirgin azalma.

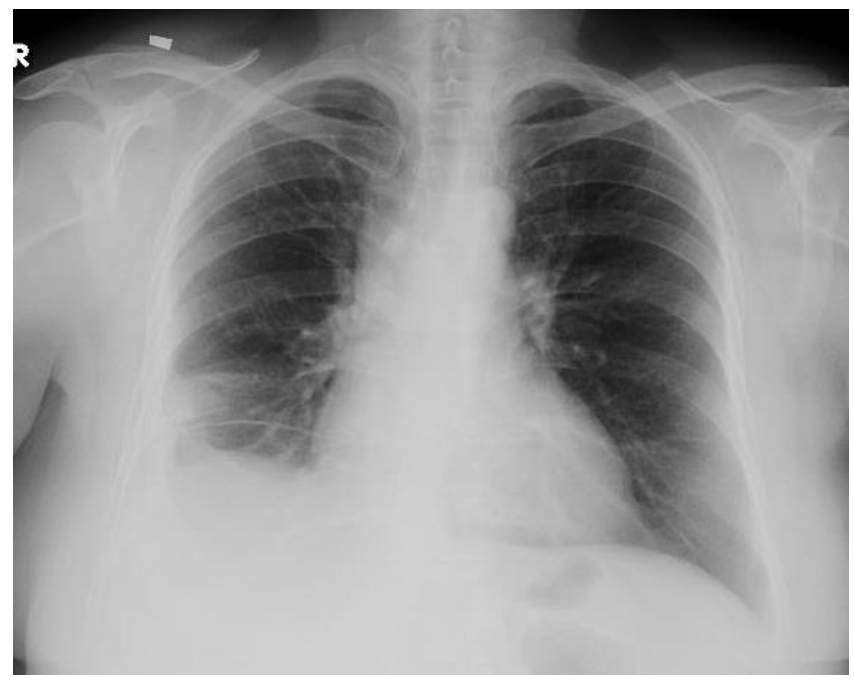

Şekil 4: iki ay sonraki kontrol grafisinde hemotoraks miktarında azalma devam etmekte ve sağ akciğer fibrotoraks gelişmesini gösteren volüm kaybı.

Hemotoraks tanısı genellike plevral hematokrit değerinin kan hematokrit değerine oranının \%50'den fazla olması ile konmaktadır. Bununla birlikte hemotoraksın başlamasından birkaç gün sonra dilüsyon oluşmakta ve bu oran \%25-50 arasında yer almaktadır (11). Genellikle travma sonucunda meydana gelmekledir, herhangi bir travmaya maruz kalmadan meydana gelmesi durumuna spontan veya non-travmatik hemotoraks denmektedir. Spontan hemotoraks oldukça nadir görülür ve etyolojisinde maligniteler, antikoagülan ilaçlar, damar rüptürü, endometriozis, akciğer enfarktüsü, yapışıklıkla birlikte seyreden pnömotoraks ve hemofili gibi hematolojik anormallikler vardır (11). Intraplevral boşlukta toplanan kan, diafragma, akciğerler, kalp ve diğer intratorasik yapıların hareketi ile kısmen defibrine olur ve kan tam anlamıyla pıhtılaşamaz. Kanamanın kesilmesinden sonraki saatlerde, plevral enzimler kan pıhtısını eritmeye çalışır. Eritrositlerin yıkılması ile intraplevral sıvıda protein konsantrasyonu ve buna bağlı olarak intraplevral boşluktaki onkotik basınç artar ve bu da plevral sıvının 3-4 gün içinde artmasına neden olur. Bu sırada plevral sıvının hemotokrit değeri düşer. Fibröz plevral kabuk, 4-5 haftada gelişimini tamamlar. Bazı hastalarda olay kendini sınırlayarak iyi bir gidiş gösterebilir. Yeterli tedavi edilemeyen hemotoraks geç dönemlerinde ampiyem veya fibrotoraks sebebiyet verebilir (12). Hemotorakslı olgularda uygulanan temel tedavi, kanlı sıvıyı boşaltmak ve devam eden kanamanın yoğunluğunu belirlemek amacıyla göğüs tüpü takılarak drenaj uygulanmasıdır. Bununla birlikte hemotoraks tedavisine, daha az invaziv olan torasentez ile başlanılabilmektedir (12). Derin ven trombozu 
ve pulmoner emboli saptanan hastamızda varfarin tedavisi kesilerek, yerine enoksaparin sodyum başlandı. INR değeri normale gelmesinden sonra torasentez ile toplam 700 cc hemorojik plevral sıvı boşaltıldı ve hastamızda göğüs tüpü takılmadan belirgin düzelme saptandı. Hastamızın plevral boşalıım sonrası takiplerinde iki ay sonraki grafisinde rezolüsyonunun devam ettiği ve sağ akciğerde fibrotoraks başladığını gösteren volum kaybı gözlemlenmiştir. Bu olgu ile hemotoraks tedavisinde uygun olgularda tekrarlayan torasentez yapılarak tedavi edilebileceğini vurgulamak istiyoruz.

Sonuç olarak, antikoagülan tedavi olarak varfarin kullanan hastaların, INR değeri istenilen seviyede olsa bile kanama gelişme ihtimali her zaman akılda tutulmalı, kontrollere geldiğinde mutlaka ayrıntılı anamnez alınmalı ve basit hemoglobin veya hematokrit takibi yapılmalıdır. Özellikle antikoagülan tedavi alan hastalarda plevral efüzyon görüntüsünün oluşması durumunda hemotoraks olabileceği akılda tutulmalıdır.

\section{ÇIKAR ÇATIŞMASI}

Bu makalede herhangi bir çıkar çatışması bildirilmemiştir.

\section{YAZAR KATKILARI}

Fikir - H.K., N.A., S.B., B.Y., M.H.S., H.S., M.K.; Tasarım ve Dizayn - H.K., N.A., S.B., B.Y., M.H.S., H.S.., M.K.; Denetleme - H.K., N.A., S.B., B.Y., M.H.S., H.Ş., M.K.; Kaynaklar - H.K.; Malzemeler - H.K.; Veri Toplama ve/veya İşleme - H.K., H.Ş., B.Y.; Analiz ve/veya Yorum H.K.; Literatür Taraması - H.K., S.B.; Yazıyı Yazan - H.K.; Eleştirel İnceleme - M.H.S., S.B.

\section{KAYNAKLAR}

1. Ansell J, Hirsh J, Hylek E, Jacobson A, Crowther $M$, Palareti G. American College of Chest Physicians. Pharmacology and management of the vitamin $\mathrm{K}$ antagonists: American College of Chest Physicians Evidence-Based Clinical Practice Guidelines (8th Edition). Chest 2008; 133:160s-198s. [CrossRef]

2. Eroğlu SE, Altınok Denizbaşı A, Özpolat Ç, Akoğlu H, Onur Onur ÖE, Akoğlu Ünal E. The investigation of the relation between INR levels and risk of complication in patients with a history of warfarin use. Marmara Med J 2012; 25:138-42.

3. Keeling D, Baglin T, Tait C, Watson H, Perry D, Baglin C, et al. Guidelines on oral anticoagulation with warfarinfourth edition. $\mathrm{Br} J$ Haematol 2011; 154:311-24. [CrossRef]

4. Levine MN, Raskob G, Landefeld S, Kearon C. Hemorrhagic complications of anticoagulant treatment. Chest 1998; 114:511-23. [CrossRef]

5. Veeger NJ, Piersma-Wichers M, Tijssen JG, Hillege HL, van der Meer J. Individual time within target range in patients treated with vitamin $\mathrm{K}$ antagonists: main determinant of quality of anticoagulation and predictor of clinical outcome. A retrospective study of 2300 consecutive patients with venous. Br J Haematol 2005; 128:513-9.

6. Palareti G, Leali N, Coccheri S, Poggi M, Manotti C, D'Angelo $A$, et al. Bleeding complications of oral anticoagulant treatment: an inception-cohort, prospective collaborative study (ISCOAT). Italian Study on Complications of Oral Anticoagulant Therapy. Lancet 1996; 348:423-8.

7. Landefeld CS, Beyth RJ. Anticoagulant-releated bleeding; clinical epidemiology, prediction and prevention. Am J Med 1993; 95:315-28.

8. Ansell J, Hirsh J, Dalen J, Bussey H, Anderson D, Poller L, et al. Managing oral anticoagulant therapy. Chest 2001; 119:22S-38S. [CrossRef]

9. Erkan L, Findik S, Uzun O, Atici AG, Light RW. A new radiologic appearance of pulmonary thromboembolism: multiloculated pleural effusions. Chest 2004; 126:298302. [CrossRef]

10. Light RW. Pleural diseases. 4th ed. Baltimore: MD: Lippincott Williams \& Wilkins; 2001.

11. Ali HA, Lippmann M, Mundathaje U, Khaleeq G. Spontaneous hemothorax: a comprehensive review. Chest 2008; 134:1056-65. [CrossRef]

12. Akay H. Hemotoraksta tanı ve tedavi yaklaşımı. Solunum 2002; 4:195-205. 